\title{
LOS ACUERDOS REPARATORIOS A LA LUZ DEL CONCEPTO DE REPARACIÓN
}

\author{
Lino Videla Bustillos*
}

1. Consideraciones preliminares; 2. La reparación; 3. Las salidas alternativas; 4. Los acuerdos reparatorios: a) Proyecto del Ejecutivo; b) Discusión parlamentaria; c) Fundamentos; d) Concepto; e) Requisitos de procedencia: i) Acuerdo entre victima e imputado; ii) Tipos de delitos respecto de los que procede; f) Objeto del acuerdo reparatorio; g) Oportunidad para celebrar el acuerdo reparatorio; h) Aprobación judicial de los acuerdos reparatorios; i) Rechazo del acuerdo reparatorio; j) Efecto de la aprobación de los acuerdos reparatorios: i) Efectos penales; ii) Efectos civiles; iii) Efectos subjetivos; 5. Dificultades que se han presentado en la aplicación de los acuerdos reparatorios; a) Criterios de actuación propuestos por el Ministerio Público; b) ¿Qué debemos entender por interés público prevalente?; c) Delitos sin victima; Bibliografía.

\section{Consideraciones preliminares}

El sociólogo alemán Ulrich Beck utilizó el concepto de Risikogesellschaft, que se puede traducir como sociedad del riesgo o sociedad de riesgos, para caracterizar el modelo social postindustrial en que se desenvuelve actualmente la vida del hombre. ${ }^{1}$

Esta sociedad surge, nos señala el autor, cuando los peligros decididos y producidos socialmente exceden los límites de la seguridad ya que, al mismo tiempo que se desarrolla la industria, aumentan los riesgos que dicho desarrollo lleva consigo. Así, señala Núñez, “...muchos de los problemas y conflictos que se generan en la sociedad vienen determinados por conflictos y problemas creados por la producción, definición y distribución de los riesgos que la técnica y la ciencia comportan...".

Por lo anterior, Silva Sánchez afirma que una de las consecuencias de la sociedad del riesgo es la configuración del riesgo de procedencia humana como fenómeno social estructural, es decir, “...que buena parte de las amenazas a que los ciudadanos estamos expuestos provengan precisamente de decisiones que otros conciudadanos adoptan en el manejo de los avances técnicos: riesgos para el medioambiente o para los consumidores o usuarios que derivan de las aplicaciones

\footnotetext{
* Licenciado en Ciencias Jurídicas de la Universidad de Chile. Abogado del Consejo de Defensa del Estado; email: linovidela@cde.cl

${ }^{1}$ Beck, Ulrich: Risikogesellschaft. Auf dem Weg in eine andere modern, 1986, citado por Kunsemüller, Carlos: "Sociedad del riesgo y Derecho penal ad hoc" en Revista de Derecho, Criminología y Ciencias Penales, No 4, 2002, p. 111.

2 Núñez, Raúl: “Los procedimientos del derecho penal moderno y del derecho penal clásico", en Estado de Derecho y Reformas a la Justicia, Universidad de Chile, Heilderberg Center para América Latina, California Western School of Law, Santiago, 2004, p. 82.
} 
Videla - Los acuerdos reparatorios a la luz del concepto de reparación

técnicas de los desarrollos en la biología, la genética, la energía nuclear, la informática, las comunicaciones, etcétera...”’3.

En este contexto, el ordenamiento jurídico extrapenal aparece insuficiente para hacer frente a estos males, ya que ni el derecho administrativo ni el derecho civil ofrecen una respuesta satisfactoria como instancias de protección, recurriendo el legislador al Derecho Penal para enfrentar estos peligros y recomponer la seguridad perdida por la sociedad, todo dado por su hipotética efectividad. Mendoza señala que se trata “...no sólo de la ampliación cualitativa que lleva a definir nuevos comportamientos penalmente relevantes o del aumento puramente cuantitativo de la reacción punitiva, sino de un desarrollo que se produce en un contexto más amplio en el que destacan distintos rasgos que tienen en común su carácter expansivo y una inclinación a la anticipación de la intervención penal, auspiciada por demandas crecientes de seguridad, cuya satisfacción se cree poder obtener -únicamente- a través de una más amplia y más intensa protección penal...". La autora ya señalada resalta los siguientes aspectos de la sociedad del riesgo:

1. El cambio en el potencial de los peligros actuales en relación con los de épocas pasadas. Los peligros que actualmente enfrenta la sociedad son artificiales, en el sentido de que son producidos por la actividad del hombre y vinculados a una decisión de éste, a diferencia de los peligros que amenazan con desastres naturales o plagas de otras épocas. Estos riesgos no son sólo de una magnitud creciente frente a peligros naturales, sino que son de grandes dimensiones, es decir, amenazan a un número indeterminado y potencialmente enorme de personas e incluso amenazan la existencia de la humanidad como tal.

2. La compleja organización de las relaciones de responsabilidad, en cuanto ésta se ramifica o distribuye cada vez más a través de procesos en los que contribuyen muchas personas, a veces integrados en un sistema de división del trabajo, pero otras sin relación entre ellos.

3. Una creciente sensación de inseguridad subjetiva que experimentan los miembros de la sociedad, aun cuando objetivamente vivan en especiales condiciones de seguridad y con independencia de la existencia de reales peligros.

4. El desarrollo de una específica política criminal para la sociedad del riesgo, caracterizada por una tendencia al derecho penal preventivo con un acentuado adelantamiento de la protección penal (formulación de delitos de peligro y configuración de bienes jurídicos universales de vago contenido).

\footnotetext{
${ }^{3}$ Silva Sánchez, Jesús María: La expansión del derecho penal. Aspectos de la política criminal en las sociedades postindustriales, Editorial Civitas, Madrid, 2001, pp. 27 ss.

${ }^{4}$ Mendoza B., Blanca: El Derecho Penal en la sociedad del riesgo, Editorial Civitas, Madrid, 2001, p. 21.
} 
Como consecuencia de todo lo anterior, la población se siente indefensa frente a estos males y se ve a sí misma como potencial víctima de un delito, pasando a ser tema prioritario el miedo y la inseguridad. El legislador se ha visto forzado a realizar un giro en su concepción del proceso penal, otorgando mayor relevancia a la participación de la víctima y a sus demandas de reparación.

Una clara acogida de los postulados de la sociedad del riesgo la encontramos en la reforma llevada a cabo en nuestro país, con la cual pasamos de un sistema inquisitivo en el cual la víctima no era titular de derechos y sólo era considerada como objeto de prueba, a uno contradictorio en el cual la víctima es sujeto de derechos, teniendo, entre otros, derecho a intervenir activamente en la persecución penal y a ser reparada.

Es dentro de este marco en que las distintas legislaciones han debido ingeniárselas para crear mecanismos que den respuesta a las demandas de seguridad de los ciudadanos, generándose procedimientos más simplificados y de menor duración, descongestionando el sistema penal y dando cabida a instituciones que permiten suspender o hacer cesar la persecución penal cuando la víctima sienta que ha sido reparada en el mal que se le ha causado. Uno de estos mecanismos lo constituyen los acuerdos reparatorios, que son la más clara manifestación de nuestro legislador de su giro hacia la víctima del delito y de acogida a los postulados de la sociedad del riesgo.

\section{La reparación}

En palabras de la profesora María Inés Horvitz, Tiedeman sostiene que la finalidad del proceso penal es buscar la verdad respecto del hecho punible y castigar al autor para, de este modo, restablecer la validez de la norma lesionada ${ }^{5}$, independientemente de los mecanismos que se utilicen para conseguirla.

En este escenario donde lo que se busca es la verdad respecto del ilícito cometido, no hay lugar para la negociación, salvo la que se produce entre el inculpado y el órgano jurisdiccional en atención a recibir ciertos beneficios a la hora de ser enjuiciado, si coopera en la investigación. Como apunta Hassemer, el Derecho Penal está unilateralmente orientado hacia el autor del delito, y las víctimas son tomadas en cuenta tan sólo desde el punto de vista del autor del delito, como meros puntos de referencia de la intervención estatal y de la exigencia de responsabilidad penal. ${ }^{6}$

\footnotetext{
${ }^{5}$ Horvitz Lennon, María Inés: “Algunas formas de acuerdo o negociación en el proceso penal: Tendencias en el Derecho Comparado”, en Revista de Ciencias Penales, Tomo LX, No 2, Santiago, 1994.

${ }^{6}$ Hassemer, Winfried: Fundamentos del Derecho Penal, J. M. Bosch Editor, Barcelona, 1984.
} 
Es por esto que la negociación se ha manifestado en aquellos sistemas en los que el proceso penal se concibe como mecanismo de solución de los conflictos, y no de búsqueda de la verdad sobre los hechos.

Para Roxin, si a causa del principio de culpabilidad no se justifica la imposición de una pena o medida de seguridad, en el sentido de que éstas satisfagan fines preventivos generales y especiales, entonces a causa del principio de subsidiariedad se podría justificar la inclusión de la reparación como tercera vía. ${ }^{7}$

Para Bustos, en cambio, nunca se puede llegar a confundir la pena con la sanción reparadora el sistema no podría tener como única finalidad del proceso penal la sanción reparadora, ya que entonces la amenaza penal provocada por la amenaza de imposición de una pena se vería disminuida a tal nivel, que desaparecerían las garantías de un estado de derecho respecto a los intereses privados. ${ }^{8}$

La idea de reparar tiene muchos más sentidos que la entrega de dinero del delincuente a la víctima cuando hablamos de reparación no nos referimos a una simple cuestión matemática; no se trata de otorgarle un valor a cada delito y hacer una especie de catastro señalando el delito y el monto de su reparación. Aquí de lo que se trata es de menguar el daño que ha sufrido la víctima con ocasión del hecho ilícito, razón por la que, es esta la que va a determinar cuál es la forma de disminuir el daño que se le ha causado, atendiendo entre otras cosas a criterios de proporcionalidad y a las capacidades del imputado; en este sentido el concepto de reparación es un concepto amplio.?

Por esto no es necesario que se trate siempre de una suma de dinero, lo que es beneficioso tanto para la víctima como para el imputado, pues existirán algunos casos en los que al ofendido le interese a modo de indemnización una prestación de servicios, una disculpa pública o cualquier otra prestación, lo que otorga a la reparación una infinidad de posibilidades para solucionar el conflicto, ya que no se encuentra limitada al dinero, y por otro lado, también habrá varios casos en que el inculpado será de escasos recursos y no tendrá dinero para compensar pecuniariamente a la víctima, no obstante tener todas las intenciones de enmendar el daño que provocó. De no existir este concepto amplio de reparación,

\footnotetext{
${ }^{7}$ Roxin, Claus: Derecho penal, parte general, Tomo I: La estructura de la teoría del delito, $2^{\mathrm{a}}$ edición, Editorial Civitas, Madrid, 1997, p. 109, señala: "La legitimación político-jurídica de la reparación del daño como una "tercera vía" de nuestro sistema de acusaciones la proporciona el principio de subsidiariedad".

8 Bustos Ramírez, Juan: Manual de derecho penal, parte general, $3^{\text {a }}$ edición, Editorial Ariel S.A., Barcelona, 1989, pp. 416-417.

${ }^{9}$ Duce, Mauricio: "La suspensión condicional del procedimiento y los acuerdos reparatorios en el nuevo Código Procesal Penal”, en VV.AA: Nuevo Proceso Penal, Editorial Conosur, Santiago, 2000.
} 
estaríamos hablando más que de una tercera vía de una vía discriminatoria, que sólo podría ser utilizada por delincuentes con cierto poder adquisitivo.

En cuanto a su naturaleza jurídica, Seelman y Rossner plantean la reparación como un fin penal autónomo. El primero de estos autores nos plantea la posibilidad de considerar la reparación dentro del contexto del derecho penal, pues contendría las características fundamentales que se han atribuido habitualmente a la pena: la irrogación de un mal, que viene a expresar un reproche público del hecho. La reparación podría considerarse como un fin autónomo dentro del sistema penal, al igual que la pena y las medidas de seguridad, y cuya importancia radica en que trae paz social. En palabras de Seelman: "El derecho penal se orienta según ello también al fin de una conciliación entre el autor por un lado, y la víctima y la sociedad por otro, y el apaciguamiento de estas relaciones sociales adquiere actualmente en el derecho penal de modo palpable una importancia creciente. Ello quizá podría justificar la caracterización de la reparación como particular fin de la pena". ${ }^{10}$ Rossner, por su parte, considera que la reparación, como un mecanismo a través del cual el autor de un delito realiza una prestación concreta a la víctima y una simbólica a la sociedad, constituiría el elemento esencial de control de conflictos con el efecto del restablecimiento de la paz jurídica. Un derecho penal de semejantes características sería un derecho penal del hecho de carácter positivo, que se entiende que en esta, “... dirige la mirada al punto de partida de la alteración de la convivencia de las personas y al conflicto subsistente con el fin de un tratamiento y transformación constructiva del hecho. Un tratamiento referido al hecho de esta índole, impide, por una parte, injerencias desmedidas en ámbitos de la personalidad del autor, que no tienen relación ninguna con el hecho, y por otra parte, no significa un abandono del pensamiento de la resocialización, en el sentido central de integración a través de la superación de las consecuencias del hecho y de actualización normativa individual. Aquí reside entonces, la clave teórico-penal para la superación de la crisis de sentido actual del derecho penal. A modo de consigna podría sintetizarse: reparación en lugar de contragolpe y responsabilidad en lugar de tratamiento". ${ }^{11}$

También, destaca la posición de los germanos Sessar, Frehsee y Roxin, quienes consideran la reparación como tercera vía del derecho penal o sanción autónoma dentro del sistema penal. Sessar ${ }^{12}$ plantea que la reparación tiene características de sanción con rasgos punitivos y por ello podría considerarse como una sanción autónoma dentro del sistema penal. Para él lo determinante sería establecer si en el conflicto penal se encuentra comprometido un interés privado o público.

\footnotetext{
10 Seelman, Kurt: Strafżecke und Wiedergutmachung, 1981, pp. 44-45, citado por Pérez Sanzberro, Guadalupe: Reparación y Conciliación en el Sistema Penal, Editorial Comares, Granada, 1999, p. 214.

11 Marks, Erich/Rossner, Dieter: Tater-Opfer-Ausgleich. Vom zwischenmenschlichen Wen zur Wiederhertellung des Rechtsfriedens, 1989, citado por Pérez Sanzberro, Guadalupe: Reparación y Conciliación ... (nota 10), p. 217.

12 Pérez Sanzberro, Guadalupe: Reparación y Conciliación... (nota 10), pp. 222-227.
} 
Frehsse $^{13}$ sería según Pérez Sanzberro, el primer autor en referirse a la reparación como "tercera vía", denominación que hizo conocida Roxin, concibiendo con ello que la reparación puede considerarse como un instrumento de control de índole jurídico-penal, que puede ocupar una posición intermedia en la estructura del derecho penal entendido a través de las penas y de las medidas de seguridad. Para él, la reparación puede introducirse dentro del sistema tradicional del derecho penal como una sanción autónoma, ya que con ello se le otorga a la reparación un contenido o fundamento de índole penal y no civil, esto es: con la reparación no se trataría de resarcir daños, sino que constituiría una forma de respuesta del Estado, que a su vez es un reproche, respecto de una conducta tipificada en la ley como delito.

Roxin, por su parte, considera que hay argumentos suficientes para concebir la reparación como una "tercera vía", pues con ello se serviría más a los intereses de las víctimas que con una pena privativa de libertad o con una multa. En este sentido, expresa: "Investigaciones empíricas también han demostrado que tanto el lesionado como la comunidad otorgan nulo o escaso valor a un castigo adicional del autor entre la reparación del daño en la forma de una composición autor-víctima, en casos de pequeña o mediana criminalidad. De ahí que, en casos que actualmente se castigan con una pequeña pena de multa, se podría prescindir de la pena cuando se produce una reparación total del daño; y en delitos más graves, la reparación del daño podría originar de todos modos una remisión condicional de la pena o una atenuación obligatoria de la pena". ${ }^{14}$

Dentro de los beneficios o argumentos a favor expuestos por Roxin, que en su mayoría corresponden a los dados por los autores antes mencionados y que básicamente se centran en la satisfacción de los intereses de la víctima, también toma en consideración los intereses del delincuente, y llama la atención que se refiera a la resocialización de éste, tema poco analizado por los autores anteriores, y en este sentido, la reparación constituiría una mejor alternativa de reacción frente al delito, tanto para la víctima como para el delincuente.

Para Roxin, la reparación debe entenderse como una forma de reacción a la que puede recurrir el derecho penal en la medida que satisfaga las necesidades de prevención general y especial, siendo lo deseable desde el punto de vista políticocriminal entender la reparación como una respuesta orientada a la conciliación víctima-autor. ${ }^{15}$ Sin embargo, Roxin no considera que la reparación sea un fin de la pena, ni que pueda llegar a serlo, sino que más bien la visualiza como una herramienta necesaria y eficaz desde el punto de vista de la prevención, tanto

\footnotetext{
13 Ibid., pp. 227-235.

${ }^{14}$ Roxin, Claus: Derecho penal parte general (nota 7), p. 109.

15 Roxin, Claus: "Die Wiedergutmachung im system der Strafzwecke", en Schoch (Ed.), Wiedergutmachung und Strafrecht, 1987, pp. 62-63, citado por Pérez Sanzberro, Guadalupe: Reparación y Conciliación... (nota 10), p. 236.
} 
general como especial, y de hecho elabora la utilidad de la reparación a través de los conceptos de prevención general negativa, prevención general positiva y prevención especial. En este sentido, estimamos que Roxin acierta cuando expresa que la reparación puede ser considerada una tercera vía del Derecho Penal, independientemente de las penas y de las medidas de seguridad, pero cuyo fundamento o base radica en que constituiría una herramienta útil para lograr los fines preventivos-generales y preventivos-especiales del Derecho Penal. De esta manera, la reparación no podría ser utilizada cuando las necesidades preventivas, tanto generales como especiales, requieran la imposición de una pena o de una medida de seguridad. ${ }^{16}$

\section{Las salidas alternativas}

Las salidas alternativas son aquellas formas en que el Estado responde de manera diferente al proceso penal y a la aplicación de una pena. Representa una respuesta de menor contenido represivo, pero de mayor calidad si lo comparamos con una pena privativa de libertad, ya que cumple con mayor certeza con el carácter resocializador al que un sistema penal debe aspirar.

El concepto de salidas alternativas engloba mecanismos con objetivos diferentes: de selección de casos, de simplificación procesal y de solución de conflictos sociales sobre la base de una alternativa a la persecución penal tradicional y a la aplicación de una pena como consecuencia de ella ${ }^{17}$.

Los mecanismos de solución de los conflictos penales, que son diferentes a la respuesta tradicional que significa la persecución penal y la posterior aplicación de una pena, son las denominadas salidas alternativas propiamente tales, que corresponden a la suspensión condicional del procedimiento (artículo $237 \mathrm{CPP}$ ) y a los acuerdos reparatorios (artículo $241 \mathrm{CPP}$ ). Ambas instituciones representan un cambio radical en la forma de enfrentar el conflicto penal. Se oponen al principio tradicional que rige nuestro sistema procesal penal, cual es la legalidad procesal, la que hasta la reforma no reconocía la existencia de fórmulas y mecanismos informales de resolución de conflictos, como son las tratativas y negociaciones de los abogados de las partes fuera de la sede judicial, y que generalmente terminaban con el conflicto.

\footnotetext{
16 Roxin, Claus: “Zur Wiedergtmachung als einer dritten Spur im Sanktionen-system”, en Art/Fezer/Weber/Schluchter/Rossner (Eds.), Festchrift fur Jurgen Baumann zum 70. Geburtstag, 1992, pp. 243-254, citado por Pérez Sanzberro, Guadalupe: Reparación y Conciliación ... (nota 10), p. 236.

17 Zárate Campos, M: "Los Acuerdos Reparatorios: Algunos comentarios a partir de las nociones de reparación y negociación”, tesis presentada en el Diplomado sobre Reforma Procesal Penal: aspectos dogmáticos, legales y de litigación en juicio oral, Universidad Católica del Norte, sede Coquimbo, septiembre 2001. www.acceso.uct.cl/congreso/docs/mzarate.doc
} 
Videla - Los acuerdos reparatorios a la luz del concepto de reparación

\section{Los acuerdos reparatorios}

El Código Procesal Penal recoge a esta institución, en el Párrafo $6^{\circ}$, del Título I, del Libro Segundo, que se titula "Suspensión condicional del procedimiento y acuerdos reparatorios". En el artículo 241 nos señala:

"Procedencia de los acuerdos reparatorios. El imputado y la víctima podrán convenir acuerdos reparatorios, los que el juez de garantía aprobará, en audiencia a la que citará a los intervinientes para escuchar sus planteamientos, si verificare que los concurrentes al acuerdo hubieren prestado su consentimiento en forma libre y con pleno conocimiento de sus derechos.

Los acuerdos reparatorios sólo podrán referirse a hechos investigados que afectaren bienes jurídicos disponibles de carácter patrimonial, consistieren en lesiones menos graves o constituyeren delitos culposos.

En consecuencia, de oficio o a petición del Ministerio Público, el juez negará aprobación a los acuerdos reparatorios convenidos en procedimientos que versaren sobre hechos diversos de los previstos en el inciso que antecede, o si el consentimiento de los que lo hubieren celebrado no apareciere libremente prestado, o si existiere un interés público prevalente en la continuación de la persecución penal. Se entenderá especialmente que concurre este interés si el imputado hubiere incurrido reiteradamente en hechos como los que se investigaren en el caso particular".

\section{a) Proyecto del Ejecutivo}

El Mensaje del CPP contiene algunas ideas que cabe destacar: en primer lugar, señala que la pena, como la típica respuesta penal, muchas veces es inadecuada ante otras maneras de solucionar los conflictos. Así, los acuerdos reparatorios surgen como una forma de instaurar un sistema que otorgue diversas posibilidades de solución de las disputas. Además que con los acuerdos se busca responder al interés de la víctima.

En un principio el proyecto se refería a los acuerdos en sólo dos artículos, el 335 y 336, que se fueron modificando tanto en la Cámara de Diputados como en el Congreso.

\section{b) Discusión parlamentaria}

La Cámara de Diputados modificó los dos artículos que se referían a los acuerdos reparatorios y se incorporaron otros. 
La Cámara justificó la incorporación de los acuerdos reparatorios, ya que se debía reconocer el interés preponderante de la víctima en aquellos delitos de carácter patrimonial y así se le devolvía protagonismo a la víctima. ${ }^{18}$

Con relación a la aplicación, se señaló que va a quedar determinada por la ley y su interpretación. ${ }^{19}$

Por su parte, en el Senado se justificó la introducción de estos acuerdos por razones económicas, ya que se dijo que si había acuerdo entre la víctima y el imputado no tenía sentido poner en movimiento toda la administración de justicia, incurriendo en mayores costos para el Estado. ${ }^{20}$

En el segundo informe de la Comisión, se agrega otro argumento, pues se señala que se recogen los intereses de la víctima y que, sin la cooperación de ésta el procedimiento no podría seguir adelante, y también se señala que se busca hacer transparente lo que ocurre hoy en la práctica y no precisamente sobre bienes disponibles. $^{21}$

\section{c) Fundamentos}

Los fundamentos de los acuerdos reparatorios están ligados a los argumentos que se señalan al estudiar las salidas alternativas, que son:

El carácter selectivo que debe tener un sistema procesal penal. Un sistema de justicia procesal penal no puede investigar todos los hechos que revisten caracteres de delito, debido a que los recursos humanos y económicos son limitados, lo que se traduce, en la práctica, que éstos deban concentrarse en la investigación de los delitos de mayor relevancia social y penal (mayor desvalor de injusto). Además, un sistema procesal que pretenda investigar todos los hechos presuntamente delictivos tendría una muy baja efectividad, lo que acarrearía como consecuencia el malestar de la sociedad.

La selectividad también la podemos enfocar desde el punto de vista que el legislador ha preferido dar un tratamiento diferenciado a determinados tipos de casos, otorgando distintas soluciones para un mismo hecho. Aquí, son las mismas partes del conflicto quienes deciden cómo solucionarlo, lo que redunda en una

\footnotetext{
18 Primer Informe Comisión de Constitución, Legislación y Justicia de la Cámara de Diputados, párrafo referente al artículo 315, en Maturana Míquel, Cristián: Reforma procesal penal, Tomo III, Editorial Libromar, Santiago, 2002, p. 313.

${ }^{19}$ Ibid.

20 Primer Informe Comisión de Constitución, Legislación y Justicia y Reglamento del Senado; Discusión General; punto 1.1 Acuerdos Reparatorios, en Maturana Míquel, Cristián: Reforma Procesal Penal (nota 18), p. 315.

${ }^{21}$ Segundo Informe Comisión de Constitución, Legislación y Justicia y Reglamento del Senado; resumen de los principales acuerdos; I Disposiciones que se mantienen; punto 1: Salidas Alternativas, en Maturana Míquel, Cristián: Reforma procesal penal (nota 18), p. 315.
} 
Videla - Los acuerdos reparatorios a la luz del concepto de reparación

economía tanto procesal como de recursos económicos, porque los medios que se iban a utilizar en la investigación y posterior enjuiciamiento de una situación determinada ahora se podrán dirigir a la investigación de hechos de mayor relevancia.

El fomento de la reinserción del imputado: Los acuerdos reparatorios permiten la reinserción social principalmente por dos características: la primera dice relación con que, sin perjuicio del registro que para efectos internos llevan los órganos encargados de la persecución penal, no queda constancia de su celebración en el extracto de filiación del imputado, por lo que esto no constituye una limitante para que éste pueda desarrollar cualquier actividad o profesión en la cual dicho certificado le sea solicitado. La segunda, se refiere al hecho de que el imputado no irá a un centro penitenciario, con lo que ni él ni su familia se van a ver expuestos a relacionarse con ese ambiente.

La satisfacción concreta de los intereses de la víctima: $\mathrm{Si}$ el conflicto penal tiene su origen en la vulneración de un bien jurídicamente protegido de una persona determinada, qué duda puede caber en que el individuo más indicado para señalar la forma en que el perjuicio que se le ha causado debe ser reparado es la misma víctima.

De esta manera, se obtiene una mayor satisfacción de la víctima en los acuerdos reparatorios, en la medida que ésta sólo va a aceptar el acuerdo cuando estime que el daño que se le ha causado ha sido completamente reparado.

Son argumentos que podemos señalar a favor de la incorporación de los acuerdos reparatorios los siguientes:

- Concreción en el derecho procesal penal de algunas tendencias modernas en el derecho comparado.

- Uso adecuado y racional del principio de legalidad imperante.

- Beneficio social e individual de la aplicación priorizada de los acuerdos reparatorios.

- Mayor pertinencia de la solución vía acuerdos reparatorios a determinados problemas sociales.

- Mayor agilidad del proceso penal.

- Efecto económico de los acuerdos reparatorios.

\section{d) Concepto}

Para acercarnos a una definición de lo que se entiende por acuerdos reparatorios, vamos a exponer diversas definiciones que se han dado por distintos profesores y autores que han escrito sobre el tema, para finalmente esbozar una definición propia: 
1. Maria Inés Horvitz Lennon: Señala que esta herramienta consiste, esencialmente, "en un acuerdo entre imputado y víctima, en que el primero repara de algún modo que resulte satisfactorio para la segunda las consecuencias dañosas del hecho que se persigue penalmente y que, aprobado por el juez de garantía, produce como consecuencia la extinción de la acción penal". ${ }^{22}$

2. Raúl Tavolari Oliveros: Los acuerdos reparatorios pueden ser definidos como "convenciones celebradas entre el imputado y la víctima de índole patrimonial que, aprobadas por el respectivo juez de garantía, tienen la virtud de poner fin al proceso penal". ${ }^{23}$

3. Alex Carocca Pérez: Los define señalando que "es una salida alternativa que procede cuando se investigan hechos presuntamente delictivos que afecten bienes jurídicos disponibles de carácter patrimonial, de lesiones menos graves $\mathrm{o}$ cuasidelitos, y se conviene directamente entre la víctima y el imputado el pago de una indemnización económica o de otro tipo que, al ser aprobada por el juez de garantía, extingue la responsabilidad penal". ${ }^{24}$

4. Mauricio Duce: Los acuerdos reparatorios pueden ser descritos como "una salida alternativa al proceso penal en virtud de la cual se puede extinguir la acción penal tratándose de cierta categoría de delitos, cuando existe entre la víctima y el imputado un acuerdo de reparación prestado en forma libre y voluntaria y este acuerdo es, además, aprobado por el juez de garantía a cargo del respectivo caso". ${ }^{25}$

5. Concepto propio: Los acuerdos reparatorios son un acto jurídico procesal, en virtud del cual víctima e imputado llegan a un consenso que dice relación con la forma de solucionar el conflicto que los enfrenta, que procede respecto de determinados delitos, en el cual el imputado acuerda con la víctima reparar el daño que ha sufrido a través de una prestación que puede tener la más variada naturaleza, en la que la víctima debe prestar su consentimiento en forma libre y voluntaria, siendo dicho acuerdo aprobado por el respectivo juez de garantía y poniendo de esta forma fin al conflicto penal.

\footnotetext{
${ }^{22}$ Horvitz L., María Inés y López M., Julián: Derecho procesal penal chileno: Principios; Sujetos procesales; Medidas Cautelares; Etapa de Investigación. Tomo I, Editorial Jurídica de Chile, Santiago, 2003, pp. 568569.

23 Tavolari O., Raúl: "Excepciones al principio de legalidad y salidas alternativas en el nuevo Código Procesal Penal", en Materiales de estudio para estudiantes. Universidad de Chile, 2000, p. 52.

${ }^{24}$ Carocca P., Alex: El Nuevo Proceso Penal, Editorial Jurídca Conosur, Santiago, 2000, p 181.

${ }^{25}$ Duce, Mauricio: “La Suspensión Condicional...” (nota 9), p. 140.
} 


\section{e) Requisitos de procedencia}

Los acuerdos reparatorios requieren la concurrencia de dos elementos: la existencia de un acuerdo de reparación entre el imputado y la víctima; y que dicho acuerdo recaiga sobre una determinada categoría de delitos.

\section{i) Acuerdo entre víctima e imputado}

El primer requisito dice relación con que concurran las voluntades del imputado y de la víctima en el acuerdo, en términos tales que el primero esté dispuesto a reparar el daño causado y el segundo esté dispuesto a aceptar dicha reparación. Lo anterior importa que el imputado y la víctima deben estar de acuerdo (1) en la celebración del acuerdo reparatorio, (2) en la prestación a realizar por parte del imputado, (3) como así también en las modalidades y plazos para cumplirla.

Ambos deben prestar dicho consentimiento de manera libre, es decir, sin ser coaccionados, y con pleno conocimiento de sus derechos. Esto significa, especialmente, que el imputado debe ser informado de su derecho a continuar con el proceso hasta que se dicte sentencia en un juicio oral y público, como también debe ser informado de las consecuencias de la celebración o no celebración del acuerdo reparatorio, correspondiendo a la defensa el papel de asegurar que el imputado exprese su voluntad de esta forma. La víctima, por su parte, debe ser informada especialmente del hecho de que con la celebración del acuerdo reparatorio se extingue la responsabilidad penal del imputado y, en caso de que éste no cumpla con lo pactado, no podrá reiniciar la persecución penal contra él, sino que deberá dirigirse ante los tribunales civiles a fin de hacer cumplir de manera forzada el contenido del acuerdo reparatorio. ${ }^{26}$

Cabe hacerse la pregunta de si la concurrencia de la voluntad del imputado importa reconocimiento de su culpabilidad o simplemente una aceptación de los hechos que motivan la persecución. El artículo 335 del CPP responde esta interrogante al señalar que: "No se podrá invocar, dar lectura ni incorporar como medio de prueba al juicio oral ningún antecedente que dijere relación con la proposición, discusión, aceptación, procedencia, rechazo o revocación de una suspensión condicional del procedimiento, de un acuerdo reparatorio o de la tramitación de un procedimiento abreviado”. Esto significa que el imputado sólo manifiesta su voluntad de acceder a esta salida alternativa y no reconoce culpabilidad o la veracidad de los hechos que se le imputan.

Si bien el acuerdo debe ser celebrado entre el imputado y la víctima, cabe preguntarse cuál es el rol que juega el fiscal en este concierto, y en este sentido

\footnotetext{
${ }^{26}$ Lo anterior será posible siempre que el acuerdo reparatorio consista en una prestación de contenido patrimonial o en una prestación estimable en dinero, ya que en caso contrario no habrá forma de exigir su cumplimiento forzado, como por ejemplo, en el caso en que el imputado se comprometió a pedir disculpas a la víctima.
} 
compartimos lo señalado por Horvitz, quien nos dice: “...el ministerio público podría entrenar a los fiscales para facilitar la mediación entre imputado y víctima y promover acuerdos posibles de cumplir para el imputado. El mismo comportamiento podría ser practicado por los jueces de garantía. De este modo, se evitaría que para el sujeto económicamente débil pero dispuesto a colaborar la única reacción penal disponible sea la prisión", ${ }^{27}$

Esta idea de promover la celebración de acuerdos por parte del fiscal se encuentra sustentada además por el mismo Código Procesal Penal, ya que la ley $\mathrm{N}^{\circ}$ 19.789 , de 30 de enero de 2002, incorporó un inciso segundo a su artículo $6^{\circ}$, que señala: "El fiscal deberá promover durante el curso del procedimiento acuerdos patrimoniales, medidas cautelares u otros mecanismos que faciliten la reparación del daño causado a la víctima. Este deber no importará el ejercicio de las acciones civiles que pudieren corresponderle a la víctima”.

Por tanto, si bien como señalamos al principio de este acápite, el acuerdo debe ser celebrado entre víctima e imputado, el fiscal debe promover la celebración de estos acuerdos como una forma de evitar que juicios de poca monta o de escasa relevancia jurídico-penal lleguen a juicio oral y, además, para evitar que el uso de este mecanismo de solución de conflictos quede entregado a la capacidad económica de los participantes, ya que en este escenario sería de uso exclusivo de las personas de mayor capacidad económica y escaparía a las finalidades que tuvo presente el legislador al momento de su incorporación.

\section{ii) Tipos de delitos respecto de los que procede}

El artículo 241, en su inciso segundo, nos señala los tipos de delitos respecto de los cuales proceden los acuerdos reparatorios, que son: aquellos que afecten bienes jurídicos disponibles de carácter patrimonial, consistan en lesiones menos graves, o constituyan un delito culposo.

Siguiendo a Rojas, se trata de hechos punibles en que, en principio, los intereses concretos de las partes priman por sobre el interés abstracto de la sociedad en la persecución penal y la pena. ${ }^{28}$

Delitos que afecten bienes jurídicos disponibles de carácter patrimonial: Antes de empezar, debemos recordar que los bienes jurídicos son aquellas condiciones básicas de la vida social que permiten el desarrollo del individuo en sociedad y que exigen una protección por la vía penal.

\footnotetext{
${ }^{27}$ Horvitz L., María Inés y López M., Julián: Derecho procesal penal chileno... (nota 22), p. 570.

28 Rojas V., Sonia y Rojas A., Luis: "Los Acuerdos Reparatorios en el Nuevo Proceso Penal”, en La victima y el testigo en la reforma procesal penal, Ministerio Público, División de atención a las víctimas y testigos, Editorial Fallos del Mes, Santiago, 2003, p. 220.
} 
A continuación, nuestro código exige que se trate de un bien jurídico disponible, lo que en la dogmática penal se ha discutido a propósito de la teoría del consentimiento. Debemos tener presente que en un Estado Democrático de Derecho, que reconoce la libertad de la persona como un derecho fundamental, en principio, todo bien jurídico es disponible, pero político-criminalmente se ponen límites a la disponibilidad dejando el consentimiento de producir un efecto excluyente del injusto.

Siguiendo a Rojas ${ }^{29}$, los primeros criterios político-criminales que debemos reconocer son aquellos implícitos en la ley, a partir de los cuales es plausible deducir posturas del legislador sobre la disponibilidad de los bienes jurídicos. Así, señala, la extinción de la responsabilidad penal como efecto del perdón del ofendido respecto de los delitos de acción privada permite inferir que, para la ley, los bienes jurídicos protegidos por los delitos de acción penal privada contemplados en el artículo 55 del CPP son disponibles. Lo anterior es confirmado por las normas del CPP que reconocen efecto extintivo de la acción penal privada a la renuncia de la víctima a ésta (Art. 56 inc. $2^{\circ}$ ), las que establecen el sobreseimiento definitivo como consecuencia del desistimiento de la querella (Art. 401) y admiten el término de la causa por la conciliación entre las partes (Art. 404).

También es posible afirmar que el hacer depender la persecución penal pública de la voluntad de la víctima (Art. $54 \mathrm{CPP}$ ) implica una postura en orden a reconocer la disponibilidad de los bienes jurídicos protegidos por estos delitos, más aun si se tiene en cuenta que la renuncia de la víctima a la persecución extingue la acción penal pública (Art. 56 inc. $3^{\circ} \mathrm{CPP}$ ). Rojas señala que la inclusión de las lesiones menos graves y leves entre los delitos de acción penal pública previa instancia particular significa que para la ley importa no sólo el bien jurídico protegido, sino también la entidad de la afección producida en éste.

Ahora bien, debemos señalar que la concesión de acción penal pública para la persecución de un delito no implica que el bien jurídico protegido por éste sea indisponible. Por ejemplo, el hurto es un delito de acción penal pública, pero el consentimiento de la víctima excluye la tipicidad (Art. 432 del Código Penal), por lo que puede sostenerse que el patrimonio es un bien jurídico disponible.

Continuando con nuestro examen, debemos ahora determinar en qué consiste que el bien jurídico disponible sea de carácter patrimonial. A nuestro entender, la intención del legislador no ha sido restringir la aplicación de los acuerdos reparatorios, pues entonces derechamente se habría referido a los delitos contra el patrimonio. Así, esta disposición admite una interpretación más amplia que aquellos delitos que vulneran solamente al patrimonio, pudiendo incluirse algunos tipos penales que protegen principalmente al patrimonio y en menor medida a otros bienes jurídicos.

${ }^{29}$ Ibid., pp. 224 ss. 
Al respecto, Horvitz señala: “A nuestro juicio la ley abrió el camino para una interpretación progresiva de este término de modo de favorecer una ampliación paulatina de casos susceptibles de acuerdo reparatorio. Así, podrían suscitarse discusiones respecto de delitos como la malversación de caudales públicos, el fraude al Fisco o la defraudación tributaria, delitos con inequívoco, pero no exclusivo componente patrimonial y en que podría discutirse la disponibilidad del bien que protegen por no tener carácter supranacional". ${ }^{30}$

En este sentido debemos decir que compartimos el criterio de la profesora Horvitz, ya que si analizamos esta institución, en especial desde la perspectiva de buscar soluciones que satisfagan los intereses de las víctimas, y de la reforma procesal penal en general, en un contexto en el que el sistema fue diseñado de manera que sólo un porcentaje muy inferior de investigaciones llegarán a juicio oral, donde las salidas alternativas, y en este caso los acuerdos reparatorios, juegan un papel principal, parece de toda lógica que lo que se busque con el tiempo es que se haga una interpretación más extensiva de la norma.

Delitos que consistan en lesiones menos graves: Esta es una categoría de delitos que no se encontraba incorporada en el proyecto original y cuya inserción se realizó durante la tramitación parlamentaria, y esto debido a que se trata de un caso que responde a los fundamentos políticos-criminales de esta institución.

Nos encontramos ante un delito que tiene asignada una pena menor, pues se sanciona con relegación o presidio menores en sus grados mínimos o con pena de once a veinte unidades tributarias mensuales, y que no obstante se encontraba excluido, ya que afecta un bien jurídico que no es patrimonial, sino que se trata de la integridad física; pero sin perjuicio de lo anterior, es un delito cuyos efectos no son tan perniciosos para la víctima, puesto que dentro de la categoría del delito de lesiones, las menos graves corresponden a las de menor entidad, en que la víctima si bien ha sido objeto de un daño, este daño es de menor consideración, por lo que nos parece razonable su inclusión.

Se ha planteado la duda sobre la procedencia de los acuerdos reparatorios respecto de las lesiones leves tipificadas por el art. $494 \mathrm{~N}^{\circ} 5$ del Código Penal, ya que el Art. 241 inc. $2^{\circ} \mathrm{CPP}$ sólo se refiere a las lesiones menos graves. Rojas ${ }^{31}$ señala que este punto ha sido aclarado por el Juzgado de Garantía de Loncoche, en el fallo RUC No $5568-5$ del año 2001:

Tercero: Que el acuerdo reparatorio propuesto en esta causa es jurídicamente procedente, a pesar de que el artículo 241 inciso $2^{\circ}$ del Código Procesal Penal prescribe que sólo se referirá a lesiones menos graves, toda vez que, en realidad, lo que el texto de la norma

\footnotetext{
${ }^{30}$ Horvitz L., María Inés y López M., Julián: Derecho procesal penal chileno (nota 22), p. 571.

${ }^{31}$ Rojas V., Sonia y Rojas A., Luis: “Los Acuerdos Reparatorios...” (nota 28), p. 220.
} 
quiere decir es que los jueces deben negar la aprobación de los acuerdos reparatorios en caso de que los hechos investigados se refieran a lesiones de mayor intensidad que las lesiones menos graves, porque razonando a fortiori, si la ley permite que los acuerdos reparatorios se refieran a hechos investigados que consistieren en lesiones menos graves, entonces con mayor razón los autoriza tratándose de lesiones leves que dieron inicio a este procedimiento.

Delitos culposos: Como antecedente, cabe señalar que durante la tramitación parlamentaria se pretendió plantear restricciones a este grupo de delitos. La limitación operaba a nivel de la entidad del resultado producido, es decir, no procedían los acuerdos reparatorios cuando el delito culposo atribuido al imputado hubiere producido la muerte de la víctima o le hubiere ocasionado alguna de las lesiones que implican una afección grave y permanente a la integridad física, como el cuasidelito de homicidio y el cuasidelito de lesiones graves gravísimas. Estas limitaciones fueron suprimidas en el Senado. ${ }^{32}$

En la actualidad, no existe limitación alguna para celebrar acuerdos reparatorios en los delitos culposos.

Debemos recordar que la diferencia fundamental entre los delitos en general y los delitos culposos viene dada por la falta de dolo, esto es, en los delitos culposos el infractor no tiene la intención de causar el daño, pero su conducta denota una falta de cuidado que igualmente lo hace merecedor de un reproche, lo que se traduce en que generalmente llevan asignadas una pena menor que la del respectivo delito doloso.

\section{f) Objeto del acuerdo reparatorio}

El objeto del acuerdo reparatorio puede consistir en una cantidad de dinero que satisfaga los intereses de la víctima, en algún tipo de prestación u omisión por parte del imputado, e inclusive podría tratarse de una reparación simbólica. Esto es de vital importancia, porque en la medida que exista pluralidad de objeto susceptible de ser considerado como reparación, se amplía la posibilidad de que más personas puedan acceder a esta salida alternativa, ya que de haberse limitado la reparación a una suma de dinero, se estaría restringiendo el uso de los acuerdos reparatorios a las personas con mayor capacidad económica. En este sentido, la única condición es que el objeto del acuerdo sea lícito. ${ }^{33}$

\footnotetext{
32 Pfeffer, Emilio: Código Procesal Penal. Anotado y concordado, 2a edición, Editorial Jurídica de Chile, Santiago, 2001.

33 Creemos que en el caso que el imputado se esté obligando a una prestación ilícita, la única manera que tiene el juez de garantía para no aprobar el acuerdo reparatorio es recabando si el consentimiento del imputado se ha dado de manera completamente informada. Si el juez verifica que el imputado no había sido informado de esta situación, debe proceder a rechazar el acuerdo reparatorio.
} 
Cabe hacer presente que, sin perjuicio de la reparación pecuniaria que puede existir en el acuerdo reparatorio, esto no significa que se extingan las acciones civiles derivadas del hecho punible para perseguir las responsabilidades pecuniarias que correspondan, según las reglas del derecho civil. Es por esta razón que para la profesora Horvitz “...deba necesariamente introducirse en el acuerdo una estipulación que clausure la posibilidad cuando se considere que la suma de dinero estipulada cubre todos estos aspectos". ${ }^{34}$

\section{g) Oportunidad para celebrar el acuerdo reparatorio}

Los acuerdos reparatorios deben celebrarse en audiencia, en cualquier momento posterior a la formalización de la investigación. Si no se planteare en esa misma audiencia la solicitud respectiva, el juez citará a una audiencia especial con este fin, a la que podrán comparecer todos los intervinientes en el procedimiento; pero si ya se ha declarado el cierre de la investigación, sólo podrán ser decretados durante la audiencia de preparación del juicio oral (artículo 245 CPP).

En resumen, la oportunidad para llegar a un acuerdo reparatorio existe desde que se formaliza la investigación hasta el momento en que se realiza la audiencia de preparación del juicio oral.

La idea, para no gastar los recursos de manera innecesaria, es que el acuerdo reparatorio se materialice en las etapas iniciales de la persecución penal.

Cabe hacer presente que la ley no exige como requisito de validez del acuerdo reparatorio la presencia del defensor del imputado, a diferencia de lo que ocurre en la suspensión condicional del procedimiento, donde la presencia del defensor del imputado sí es un requisito de validez de la misma. La razón del disímil tratamiento de estas instituciones radica en los efectos que una y otro produce, puesto que los efectos de la suspensión condicional del procedimiento son más gravosos que los del acuerdo reparatorio, ya que en este último con la aprobación del acuerdo se extingue la acción penal.

En esta audiencia podrá además estar presente el fiscal del ministerio público, pues por un lado puede instar por el rechazo del acuerdo, y por otro, la aprobación del mismo le impedirá continuar con la investigación del delito de que se trate. En opinión de Horvitz, la presencia del fiscal no es un requisito señalado por la ley, por lo que perfectamente se podrían celebrar acuerdos reparatorios en ausencia del fiscal respectivo, sin perjuicio de las medidas disciplinarias que correspondan ser aplicadas por su inasistencia. ${ }^{35}$

\footnotetext{
${ }^{34}$ Horvitz, María Inés y López M., Julián: Derecho procesal penal chileno (nota 22), p. 572.

${ }^{35}$ Ibid., p. 574.
} 
Videla - Los acuerdos reparatorios a la luz del concepto de reparación

\section{h) Aprobación judicial del acuerdo reparatorio}

Una vez redactado el acuerdo y cumplidos los requisitos de procedencia, el juez de garantía debe aprobar el respectivo acuerdo reparatorio para que produzca efectos legales.

Antes de aprobar dicho acuerdo, el juez debe velar por que las partes hayan prestado su consentimiento de manera libre y con pleno conocimiento de sus derechos, es decir, el juez de garantía realiza un control de legalidad respecto del cumplimiento de los requisitos formales para alcanzar el acuerdo. A esta misma conclusión llega Rojas, quien amparada en el texto del artículo 241 CPP (“...el juez de garantía aprobará...”) señala que el tribunal está obligado a aceptar el contenido del acuerdo reparatorio convenido por las partes, sea cual sea el contenido del mismo. ${ }^{36}$

Con esto se busca evitar que las personas que tienen más poder ejerzan su influencia sobre las otras. Si no existiera este control de parte del juez en defensa de los más débiles, se haría realidad la crítica que se ha planteado en el sentido de que el derecho penal se transformaría en un instrumento que acrecentaría las diferencias entre los poderosos y los débiles en el proceso penal. Es así como la intervención del juez de garantía pone atajo a esta situación.

Para verificar la situación descrita en el párrafo anterior, el juez podrá realizar un interrogatorio a las partes en la audiencia y rechazar el acuerdo si considera que este requisito no concurre respecto de cualquiera de ellas.

\section{i) Rechazo del acuerdo reparatorio}

Respecto de las facultades judiciales para rechazar un acuerdo reparatorio, éstas son señaladas por el legislador en el inciso final del artículo en cuestión, y son:

- Cuando el acuerdo recaiga sobre hechos diversos a las categorías de delitos en que legalmente son procedentes los acuerdos reparatorios;

- Cuando estimare que el consentimiento de los que hubieren celebrado el acuerdo, no apareciere libremente prestado; $y$

- Si existiere un interés público prevalente que hace necesaria la continuación de la persecución penal. El código presume la concurrencia de este interés si el imputado hubiere incurrido reiteradamente en hechos como los que se investigan en el caso particular (artículo 241 inciso final CPP).

\footnotetext{
36 "Sólo puede negar la aprobación al acuerdo reparatorio cuando no concurren los presupuestos legales del mismo, es decir, el tribunal sólo puede ejercer un control formal, nunca de mérito...", Rojas V., Sonia y Rojas A., Luis: “Los Acuerdos Reparatorios...” (nota 28).
} 
La decisión de rechazar el acuerdo reparatorio el juez de garantía la puede adoptar de oficio o a petición del fiscal del ministerio público. En todo caso, esta resolución deberá exponer las consideraciones que fundamentan tal decisión.

\section{j) Efectos de la aprobación de los acuerdos reparatorios}

El Código Procesal Penal en sus artículos 242, 243 y 244 distingue tres tipos de efectos: civiles, penales y subjetivos, respectivamente.

En los párrafos siguientes nos referiremos a cada uno de ellos.

\section{i) Efectos penales}

El artículo 242 del CPP prescribe: "Efectos penales del acuerdo reparatorio. Una vez cumplidas las obligaciones contraídas por el imputado o garantizadas debidamente a satisfacción de la víctima, el tribunal dictará sobreseimiento definitivo, total o parcial, en la causa, con lo que se extinguirá, total o parcialmente, la responsabilidad penal del imputado que lo hubiere celebrado".

Los efectos penales de los acuerdos reparatorios son básicamente dos, de una gran connotación procesal, ya que, en primer lugar, una vez cumplidas las condiciones contraídas por el imputado o encontrándose éstas debidamente garantizadas, el juez debe decretar el sobreseimiento definitivo de la causa, esto es, la investigación llega a su fin.

Debemos hacer notar que la ley distingue en su redacción según el tipo de obligación que contrae el imputado. Así, podemos tener casos en que el imputado contrae una obligación de ejecución inmediata, como puede ser el pedir disculpas, devolver o entregar determinadas especies, pagar una suma de dinero en ese mismo momento, etc., como también podemos tener casos en que el imputado contrae obligaciones que se deben cumplir a través del tiempo, como pagar una suma de dinero en parcialidades, realizar una o más actividades en favor de la víctima, etc. En el primer caso, inmediatamente cumplida la obligación, el juez de garantía deberá dictar sobreseimiento definitivo en la causa, mientras que en el segundo caso, el juez deberá dictar el sobreseimiento definitivo una vez que la reparación se encuentre debidamente garantizada a satisfacción de la víctima.

Un segundo efecto, y como consecuencia del primero, es que se produce la extinción de la acción penal en contra del imputado, esto es: no se podrá requerir la intervención del Ministerio Público ni la intervención del aparato judicial para que indaguen y juzguen el mismo hecho que ya fue objeto de un acuerdo reparatorio, porque en la medida que coincidan los acontecimientos y los intervinientes, esto es víctima e imputado, no hay acción penal que ejercer, porque ésta se extinguió con la aprobación del acuerdo reparatorio. 


\section{ii) Efectos civiles}

La disposición contenida en el artículo 243 prescribe: "Efectos civiles del acuerdo reparatorio. Ejecutoriada la resolución judicial que aprobare el acuerdo reparatorio, podrá solicitarse su cumplimiento ante el juez de garantía con arreglo a lo establecido en los artículos 233 y siguientes del Código de Procedimiento Civil. civil".

El acuerdo reparatorio no podrá ser dejado sin efecto por ninguna acción

Los efectos civiles se encuentran muy relacionados con lo señalado en el punto anterior, puesto que una vez ejecutoriada la resolución que aprueba el acuerdo reparatorio, la víctima puede solicitar su cumplimiento ante el juez de garantía de conformidad a las normas de cumplimiento incidental del fallo (artículos 233 y siguientes del Código de Procedimiento Civil) o ante el tribunal civil competente de acuerdo con las reglas generales.

La posibilidad que le entrega el código a la víctima de exigir el cumplimiento del acuerdo en sede civil o penal es más ventajosa, ya que no la obliga a reclamar el cumplimiento del acuerdo sólo en sede civil, con toda la carga económica y personal que ello implica, pues esto significaría iniciar y proseguir un nuevo procedimiento judicial, sin perjuicio de que si la víctima lo desea puede optar por ese camino.

El problema que nos presenta esta normativa radica, por un lado, en que ante un incumplimiento por parte del imputado, la víctima sólo puede recurrir a las normas civiles para exigir su cumplimiento, en ningún caso podría dejar sin efecto el acuerdo y pedir al Ministerio Público que retomara la persecución penal, y por otra parte, sólo tiene las armas que el derecho civil le entrega para exigir su cumplimiento, esto es, podría llegar a ejecutar al imputado, pero en ningún caso podría solicitar al juez de garantía la prisión preventiva o cualquier otra medida de seguridad o coerción que se contemplan en el derecho penal.

Es por esto que el juez de garantía debiera adoptar todas las medidas necesarias destinadas a la realización efectiva y oportuna de la reparación acordada, máxime si tenemos en vista el hecho de que en nuestra legislación, a diferencia de otras, con la sola celebración del acuerdo reparatorio se extingue la responsabilidad penal del imputado, sin que sea necesario el cumplimiento efectivo de lo acordado. Esta disposición cobra aun más valor cuando nos encontramos ante una víctima de escasos recursos y que carece de los conocimientos o medios necesarios para hacer valer sus derechos ante un imputado poderoso.

El juez de garantía debe velar por que el imputado cumpla con las disposiciones que se señalaron en el acuerdo o, a falta de éstas, del modo que mejor satisfaga los intereses de la víctima. 
Además, el inciso final del artículo $243 \mathrm{CPP}$, establece que el acuerdo reparatorio ya aprobado no puede ser dejado sin efecto por ninguna acción civil. Lo que busca el legislador con esta norma es evitar que, por cuestiones formales, se obstaculice o haga imposible el cumplimiento del acuerdo reparatorio, circunstancia que podría desincentivar la utilización de esta salida alternativa. Pero sí cabría oponer excepciones al acuerdo, como, por ejemplo, el pago.

Otro tema importante a tratar y dilucidar dice relación con determinar si la celebración de un acuerdo reparatorio, y específicamente la prestación que por éste se recibe, que generalmente consistirá en una suma de dinero, trae como consecuencia la extinción de la acción indemnizatoria civil que nace de la comisión del hecho punible. En este sentido, no es mucho el material que se ha referido al asunto, pero el profesor Enrique Barros Bourie al respecto nos señala: "En este caso, la reparación consistirá típicamente en el pago de una suma de dinero, que es funcionalmente equivalente a la "pena" (y, en consecuencia, no puede ser calificada de indemnización de perjuicios); de ello se sigue que los acuerdos reparatorios no extinguen naturalmente la acción civil que nace del hecho punible". ${ }^{37}$

Con estas palabras el profesor Barros sostiene que la prestación pecuniaria que se puede pactar en sede penal, por concepto de reparación dentro del marco de un acuerdo reparatorio, no extingue la responsabilidad y consecuente indemnización de perjuicios en sede civil a que pueda dar lugar el mismo hecho. Para sostener esto se basa en los siguientes argumentos: en primer lugar, el origen tanto de la responsabilidad penal como de la civil son distintos, ya que la responsabilidad civil no emana del delito penal, sino que estará presente en la medida que se cumpla con los requisitos correspondientes. Es por esto que perfectamente podría haber responsabilidad civil sin que se cometa un ilícito penal y, por el contrario, es posible que no exista responsabilidad civil y sí responsabilidad penal, como ocurre en el caso de los delitos de peligro, en que no se llega a materializar el daño.

En segundo lugar, la diferenciación que este autor hace también encontraría sustento en la distinta finalidad de una y otra, puesto que el objeto de la reparación que se obtiene en sede penal no se condice con la finalidad de la indemnización civil, ya que lo que buscaría el acuerdo reparatorio es un efecto punitivo, esto es, sancionar al infractor por el delito que cometió, sanción que se traduce en un prestación pecuniaria. En cambio, la indemnización civil lo que busca es resarcir a la víctima de los perjuicios que tuvo que soportar producto del hecho dañoso, que puede ser o no constitutivo de delito; se busca dejar a la víctima en la misma posición que se encontraba antes de ocurrido el hecho que le provocó el daño. Barros señala lo anteriormente expuesto en los siguientes términos: “...a pesar de la naturaleza patrimonial, los acuerdos reparatorios

37 Barros Bourie, Enrique: Tratado de responsabilidad extracontractual, Editorial Jurídica de Chile, Santiago, 2006, p. 972. 
alcanzados en sede penal poseen típicamente efectos punitivos, de modo que no constituyen propiamente una indemnización civil con efectos en materia penal; tampoco se trata de una prestación convenida en el juicio penal que produzca per $s e$ efectos extintivos de la obligación indemnizatoria en materia civil". ${ }^{8}$

La tesis de Enrique Barros, anteriormente expuesta, además de pionera -ya que la determinación de la naturaleza civil o penal de la indemnización que se puede obtener por concepto de reparación no ha sido objeto de análisis en la doctrina nacional-, es discutible, puesto que si bien coincidimos con la separación que este autor hace en atención a señalar que mientras la reparación pecuniaria tiene su origen en el ilícito mismo, la indemnización civil lo tiene en los daños que la víctima puede haber sufrido como consecuencia del delito, y que por tanto ambas indemnizaciones vienen a reparar distintas responsabilidades que nacen de un mismo hecho, no compartimos el argumento en cuanto nos señala que la reparación que se obtiene en el acuerdo reparatorio es "...equivalente funcionalmente a la pena", ya que el profesor Barros le otorga una calificación jurídica a los acuerdos reparatorios que en doctrina es discutible, puesto que señalar que la reparación que se obtiene de la utilización de esta salida alternativa es una pena traería como consecuencia dar por sentado que los acuerdos reparatorios son una institución que tienen su fundamento en el derecho penal, cuestión que no se encuentra tan clara, pues si aceptamos que la prestación pecuniaria que se puede obtener a través de la celebración de un acuerdo reparatorio tiene un contenido punitivo, entonces tendría que someterse a todas las garantías y requisitos que establece el derecho penal para la imposición de una sanción, como son la existencia de un juicio previo legalmente tramitado, la determinación de la participación y culpabilidad del imputado, entre otros.

Además del análisis que en este trabajo se ha realizado de esta salida alternativa, no podemos sostener con certeza que los acuerdos reparatorios tengan una función punitiva porque, a diferencia de lo que ocurre en otros países, en nuestro derecho los acuerdos reparatorios, o más bien la reparación, no se imponen como una obligación judicial luego del establecimiento de la participación y determinación de la culpabilidad del imputado en una sentencia, sino que se establecen como una facultad que pueden hacer valer el imputado y la víctima hasta antes de la celebración de la audiencia de preparación del juicio oral.

\section{iii) Efectos subjetivos o personales}

En lo que se refiere a los efectos subjetivos o personales del acuerdo reparatorio, el artículo 244 CPP nos señala: "Efectos subjetivos del acuerdo reparatorio. Si en la causa existiere pluralidad de imputados o víctimas, el procedimiento continuará respecto de quienes no hubieren concurrido al acuerdo".

\footnotetext{
38 Ibid., pp. 972-973.
} 
En este sentido lo que hace el Código Procesal Penal es reconocer la posibilidad de que, ante la existencia de más de un imputado o de más de una víctima, no sea necesario que se llegue a un acuerdo entre todos los imputados o entre todas las víctimas, sino que se pueden ir celebrando acuerdos reparatorios sólo entre algunos de los intervinientes, y en este sentido los efectos del acuerdo reparatorio se van a producir sólo respecto de las personas que concurrieron al acuerdo.

\section{Dificultades que se han presentado en la aplicación de los acuerdos reparatorios}

A continuación, abordaremos algunos problemas que la doctrina ha detectado respecto de la redacción de las normas que consagran esta institución o de las dificultades que en la aplicación práctica se han presentado.

\section{a) Criterios de actuación propuestos por el Ministerio Público}

El ministerio público, representado a través de su fiscal nacional, tiene la facultad de dictar instructivos generales en que entrega a los fiscales criterios de actuación respecto de determinados temas.

Con relación a los acuerdos reparatorios, el fiscal nacional Guillermo Piedrabuena dictó instructivos especialmente dirigidos a esta institución en los que se plasman, entre otras cosas, los criterios de actuación que deben seguir la fiscales frente a la solicitud de esta salida alternativa por parte del imputado, de la víctima, o de ambos.

Duce ha señalado, respecto al rol que el Ministerio Público debe asumir frente a los acuerdos reparatorios, que ".... diferencia de la suspensión condicional del procedimiento, la intervención del Ministerio Público en los acuerdos reparatorios es marginal". ${ }^{39}$

En nuestra opinión compartimos lo señalado por Duce, porque al ser el acuerdo reparatorio una institución que principalmente busca satisfacer los intereses de la víctima y permitir la resocialización del imputado, parece razonable que la intervención del Ministerio Público deba ser marginal, ya que aquí lo determinante es el concierto a que lleguen los principales involucrados, esto es, víctima e imputado, y quien fiscalizará si se cumplen o no los requisitos formales de procedencia es el juez de garantía. Distinto es el caso de la suspensión condicional del procedimiento, ya que en ésta los bienes jurídicos protegidos son distintos y, por tanto, hay un interés público que resguardar, y en consecuencia, el fiscal como órgano investigador y persecutor tiene un rol principal.

\footnotetext{
${ }^{39}$ Duce, Mauricio: “La suspensión condicional del procedimiento...” (nota 9), p. 168.
} 
El señor Piedrabuena señala en el Instructivo General $N^{\circ} 34$ que el Ministerio Público debe desempeñar un rol activo con relación a los acuerdos reparatorios, ya sea propiciándolos u oponiéndose a ellos.

Es así como ha adoptado ciertos criterios que, de acuerdo a nuestro punto de vista, restringen la aplicación de esta institución. Por ejemplo, el instructivo ordena que, “...no obstante proceder un acuerdo reparatorio atendida la naturaleza del hecho punible, los fiscales pueden oponerse a la aprobación del mismo cuando constataren que el consentimiento prestado no fue libre e informado o estimaren que existe un interés público prevalente en la continuación de la persecución penal". ${ }^{40}$

Las dudas que nos surgen en este punto dicen relación con la manera en que los fiscales determinarán que no existió un consentimiento libre o informado. ¿Qué sucede, por ejemplo, en el caso de una persona que celebra un acuerdo reparatorio con la finalidad de obtener una reparación pecuniaria de la manera más rápida posible porque necesita el dinero con extrema urgencia? El fiscal, en este caso, puede alegar que no existe un consentimiento libre, ya que la persona estaba en una situación apremiante, y por lo tanto, el acuerdo se encuentra viciado. O qué sucede en el caso de que el imputado sea una persona de escaso nivel educacional, que no comprende a cabalidad el sistema judicial y sus derechos. ¿Existe en ese caso una voluntad viciada por falta de información? Son preguntas que nos surgen a la luz de las recomendaciones del ex fiscal nacional y que, por lo demás, no se condicen con los fundamentos que se tuvieron presentes al momento de introducir esta institución en el sistema procesal penal, ni tampoco dicen relación con el sistema en general.

Una segunda interrogante que se nos plantea se relaciona con los delitos respecto de los cuales proceden los acuerdos reparatorios. El señor Piedrabuena, a través del instructivo $\mathrm{N}^{\circ} 34$ antes mencionado, realiza una enumeración taxativa de los ilícitos en que los fiscales deberán favorecer la procedencia de los acuerdos reparatorios; en los que deberá hacerse una evaluación de su conveniencia; y aquéllos respecto de los cuales deberán sencillamente rechazar el acuerdo. Estos últimos son: robo con fuerza en lugar no habitado, robo de cosas en bienes nacionales de uso público, robo de cables o alambres, robo o hurto de vehículos y el abigeato, fabricación de instrumentos destinados al robo, violación no violenta de domicilio, alteración o destrucción de deslindes de propiedad pública, incendio de objetos de poco valor, daños a sistemas de tratamiento de información, delitos contra la propiedad intelectual, usura y delitos de los proveedores. La pregunta que nos surge es: ¿Qué criterios utilizó el fiscal nacional para determinar cuáles delitos pueden ser objeto de acuerdo reparatorio y cuáles no? No vemos justificación a esta iniciativa que, de acuerdo a nuestro entender, busca limitar la procedencia de los acuerdos, lo que se ve confirmado por el intento del Ministerio Público de

40 Instructivo General N ${ }^{\circ} 34$, sobre criterios de actuación relativos a los acuerdos reparatorios. Santiago, Diciembre de 2000. 
asumir un rol preponderante, cuando su misión debería ser la de confirmar el cumplimiento de los requisitos de procedencia de los acuerdos.

Consideramos que es tarea de los jueces, a través de los fallos que vayan dictando en el tiempo, y no de los fiscales, determinar los delitos en que proceden los acuerdos reparatorios y aquéllos que no son aptos para solucionarse a través de esta vía, pero que en todo caso, la normativa legal lo que hace es entregarnos las bases a partir y dentro de las cuales se debe desarrollar esta institución, con miras a una interpretación y aplicación cada vez más amplia.

\section{b) ¿Qué debemos entender por interés público prevalente?}

Este tema se encuentra relacionado con determinar la extensión de las facultades judiciales que posee el juez de garantía para rechazar un acuerdo reparatorio, ya que el artículo $241 \mathrm{CPP}$ en su inciso final nos señala que dentro de las causales por las cuales el juez de garantía puede rechazar un acuerdo reparatorio está la de considerar que existe un interés público prevalente en la continuación de la persecución penal. También, se relaciona con la iniciativa que cabe al ministerio público para solicitar el rechazo de un acuerdo reparatorio.

El Ministerio Público, a través del Instructivo $\mathrm{N}^{\circ} 34$, señala que los fiscales podrán estimar que concurre un interés público prevalente, entre otros, en los siguientes casos:

- $\quad$ La existencia de otro bien jurídico afectado de mayor entidad que el principalmente vulnerado por el delito objeto del acuerdo reparatorio.

- La constancia de haber llegado a acuerdo reparatorio por el mismo delito al menos dos veces anteriores al proceso penal.

- $\quad$ La concurrencia de agravantes objetivas.

Señala el instructivo que “(...) alegar la existencia de un interés público prevalente en la continuación de la persecución penal para negar la aprobación de un acuerdo reparatorio implica estimar que el conflicto provocado por un delito de mediana gravedad debe enfrentarse mediante la imposición de una pena y no a través de un acuerdo libre e informado de los sujetos concretamente afectados en sus intereses particulares. Por tanto, los fiscales justificarán el ejercicio de esta facultad a la luz de los fines preventivos de la pena, esto es, la prevención general o la especial, según sea el caso". ${ }^{41}$

Rojas, por su parte, entiende que “(...) la oposición significa que en el caso concreto la necesidad de persecución penal pública prepondera por sobre los intereses de las partes. Es decir, se estima que, en el caso concreto, el conflicto entre el Estado y el imputado provocado por la infracción cometida, es más

\footnotetext{
41 Ibid.
} 
importante que el conflicto entre la víctima y el imputado...". "Lo anterior vuelve sumamente dudosa la facultad que la ley concede al tribunal para negar, de oficio, la aprobación del acuerdo reparatorio. Porque tal decisión adoptada de oficio por el tribunal implicaría que, a juicio de éste, en el caso concreto, debe imponerse una pena por razones de prevención general y de prevención especial, apreciación totalmente incompatible con el rol del tribunal. Una decisión de este tipo vulneraría el principio acusatorio, que exige una separación estricta entre las facultades persecutorias y las jurisdiccionales". ${ }^{43}$

Rojas sostiene que “...la evaluación sobre la prevalencia del interés público en la persecución penal corresponde solamente a la fiscalía, puesto que ésta es la representante del interés público en los procesos penales y, en esa condición, ejerce la acción penal pública solicitando la imposición de una pena en el caso concreto (...) En consecuencia, debemos entender que la decisión de oficio del tribunal se restringe a negar la aprobación cuando se trata de delitos que no entran en el marco de procedencia o cuando el consentimiento no ha sido prestado en forma libre e informada por las partes...".

El código intenta dar luces al respecto al señalarnos un ejemplo de cuándo puede considerarse que existe este interés público: en el caso de que el imputado hubiere incurrido reiteradamente en hechos como los que se investigaren en el caso particular. Existen varias interpretaciones posibles.

En primer lugar, podemos entender que se trata de procesos penales anteriores seguidos en contra del mismo imputado por hechos similares; o bien, de varios acuerdos reparatorios celebrados por el imputado respecto de hechos similares. También, podemos sostener que es necesaria la existencia de condenas previas referidas en hechos similares a los investigados. Una interpretación acorde con la presunción de inocencia es aquella que restringe la conducta a condenas anteriores recaídas en hechos similares a los investigados, entendiendo por tales delitos los de la misma especie, definidos por el artículo 351 inc. final del CPP, esto es, que afectan a un mismo bien jurídico.

Al respecto, existe también la interrogante de saber cuál es el rol que debe jugar el juez de garantía, esto es, si es él la persona llamada por la ley a resguardar el interés público, o si sólo le corresponde un rol secundario y quien estaría llamado a velar por el interés público sería el fiscal.

Nosotros consideramos que la persona a la cual el legislador le entregó de manera general la tarea de velar por el interés público es al Ministerio Público, lo que se ve reafirmado por el artículo $3^{\circ}$ de la Ley $\mathrm{N}^{\circ}$ 19.640, Orgánica Constitucional del Ministerio Público, que señala que es este órgano el que debe

\footnotetext{
${ }^{42}$ Rojas V., Sonia y Rojas A., Luis: "Los Acuerdos Reparatorios..." (nota 28).

${ }^{43}$ Horvitz L., María I. y López M.: Julián. Derecho procesal penal chileno (nota 22).

${ }^{44}$ Rojas V., Sonia y Rojas A., Luis: “Los Acuerdos Reparatorios...” (nota 28).
} 
velar por la correcta aplicación de la ley. Al juez de garantía se le ha dotado extraordinariamente de la facultad de velar por el interés público al momento de revisar la concurrencia de los requisitos para celebrar un acuerdo reparatorio, puesto que éste puede rechazar el acuerdo de oficio o a petición del fiscal, aun discrepando de lo argumentado por el ministerio público. ${ }^{45}$ No obstante, creemos que no están claros los elementos que debe tener presente el juez de garantía al momento de oponerse a la celebración de un acuerdo, y de ser mal entendida esta facultad, se podría restringir el uso de esta salida alternativa.

Volviendo al tema de lo que se debe entender por interés público prevalente, nosotros lo concebimos como la concurrencia de determinadas circunstancias que, tenidas a la vista y analizadas en el caso concreto, llevan al juez de garantía a decidir que debe preponderar la persecución penal por sobre el interés de las partes, debiendo estas circunstancias obedecer a criterios objetivos y generales.

No obstante lo señalado precedentemente, creemos que este concepto no debe ser interpretado aisladamente, sino que se debe tratar de desarrollar en armonía con la satisfacción de los intereses de la víctima. Como ya hemos indicado, uno de los objetivos de la reforma y de la introducción de las salidas alternativas, y el objetivo de los acuerdos reparatorios en especial, es que la víctima vea reparado el daño que el delito le ha causado.

\section{c) Delitos sin víctima}

También relacionado con el sujeto pasivo del delito, encontramos los "delitos sin víctima". "Esto dice relación con lo que ocurre cuando se ven afectados bienes jurídicos colectivos o difusos. La pregunta es: ¿A quién se debe resarcir el daño causado?

Si analizamos la redacción del código, siempre se refiere a la víctima como un ente individual; sin embargo, los profesores Duce y Riego plantean que si interpretamos la norma de manera más simple, es posible que ciertas instituciones puedan representar a la comunidad para efectos de obtener un acuerdo reparatorio. ${ }^{47}$ Señalan el ejemplo de un delito que afecte al medio ambiente, en este caso, la comunidad, representada por la municipalidad o una junta de vecinos; podría concurrir a la celebración de un acuerdo reparatorio.

\footnotetext{
45 Como consecuencia de ser extraordinaria esta facultad, sostenemos que debe ser interpretada restrictivamente, de tal manera que los jueces de garantía, so pretexto de proteger el interés público, no entorpezcan la celebración de los acuerdos reparatorios.

46 Duce, Mauricio; Riego, Cristián: Introducción al nuevo sistema procesal penal, Escuela de Derecho Universidad Diego Portales, Santiago, 2002, p. 327.

${ }^{47}$ Ibid.
} 
Compartimos este planteamiento, ya que una interpretación restrictiva de la norma supondría que todo delito debería afectar a personas perfectamente individualizadas para que ellas tuviesen la oportunidad de ser reparadas. Pero es perfectamente posible que los afectados por el ilícito sean muchas personas, caso en el cual es claramente viable su representación por algún ente u organismo que busque satisfacer los intereses de dicho grupo a través de la celebración de un acuerdo de carácter reparatorio, y si a esto le agregamos la noción de reparación en sentido amplio, nada impide que todas las víctimas sean reparadas, ya sea pecuniaria o simbólicamente. Por lo general, en estos casos la comunidad estará más interesada en que una empresa que causó un gran daño ecológico lo reconozca públicamente y se comprometa a mejorar sus mecanismos de producción, a que se les entregue una cantidad de dinero.

Esta posición, sostenemos, se puede apoyar en la norma contenida en el inciso $2^{\circ}$ del artículo $111 \mathrm{CPP}$, que señala que puede deducir querella cualquier persona capaz de parecer en juicio domiciliada en la provincia, respecto de hechos punibles cometidos en la misma que constituyeren delitos terroristas, o delitos cometidos por un funcionario público que afectaren derechos de las personas garantizados por la Constitución o contra la probidad pública. Si se permite que cualquier persona entable querella en los casos que se afecten los intereses sociales relevantes ya mencionados, es decir, si se reconoce la titularidad activa difusa, también es lógico que se permita que una agrupación o entidad pueda representar a las víctimas en el caso de daño a intereses sociales relevantes. ${ }^{48}$

\footnotetext{
${ }^{48} \mathrm{La}$ discusión acerca de los requisitos que deban cumplir estas instituciones a fin ser reconocidas como representantes de la colectividad excede los fines del presente trabajo, por lo que no nos extenderemos sobre este tema. Sin embargo, creemos que debe ser resuelto jurisprudencialmente, y algunas preguntas que deberán ser contestadas son las siguientes: ¿Será necesario que estas entidades gocen de personalidad jurídica, o es suficiente con que se trate de una agrupación de hecho?; ¿Estas agrupaciones deberán ser privadas o públicas?; ¿Podrá tratarse de instituciones que persigan fines de lucro?; ¿Estas instituciones deberán cumplir con un mínimo número de asociados?
} 
REJ - Revista de Estudios de la Justicia - No 13 - Año 2010

\section{BIBLIOGRAFÍA}

* BARROS B., Enrique: Tratado de Responsabilidad Extracontractual, Editorial Jurídica de Chile, Santiago, 2006.

* BUSTOS R., Juan: Manual de derecho penal, parte general, $3^{a}$ edición, Editorial Ariel S.A., Barcelona, 1989.

* CARocca P., Alex: El Nuevo Proceso Penal, Editorial Jurídica Conosur, Santiago, 2000.

* DUCE, Mauricio: "La Suspensión Condicional del Procedimiento y los Acuerdos Reparatorios en el Nuevo Código Procesal Penal", en Nuevo Proceso Penal, VV.AA., Editorial Conosur, Santiago, 2000.

* DUCE, Mauricio y RIEGO, Cristián: Introducción al nuevo sistema procesal penal, Escuela de Derecho Universidad Diego Portales, Santiago, 2002.

* HASSEMER, Winfried: Fundamentos del Derecho Penal, J.M. Bosch Editor, Barcelona, 1984.

* HORvitZ L., María Inés: "Algunas formas de acuerdo o negociación en el proceso penal: Tendencias en el Derecho Comparado”, en Revista de Ciencias Penales, Tomo XL, No2, Santiago, 1994.

* HORVITZ L., María Inés y LÓPEZ M., Julián: Derecho procesal penal chileno: Principios; Sujetos procesales; Medidas Cautelares; Etapa de Investigación, Tomo I, Editorial Jurídica de Chile, Santiago, 2003.

* Instructivo General $\mathrm{N}^{\circ}$ 34, sobre criterios de actuación relativos a los acuerdos reparatorios, Santiago, Diciembre de 2000.

* KUNSEMÜlLER, Carlos: "Sociedad del riesgo y derecho penal ad hoc", en Revista de Derecho, Criminología y Ciencias Penales, No 4, Universidad San Sebastián, Santiago, 2002.

* MATURANA M., Cristián: Reforma procesal penal, Tomo III, Editorial Libromar, Santiago, 2002.

* MENDOZA B., Blanca: El derecho penal en la sociedad del riesgo, Editorial Civitas, Madrid, 2001.

* NÚÑ̃Z, Raúl: "Los procedimientos del derecho penal moderno y del derecho penal clásico", en Estado de Derecho y Reformas a la Justicia, Santiago, 2004.

* PÉREZ S., Guadalupe: Reparación y Conciliación en el Sistema Penal, Editorial Comares, Granada, 1999.

* PFEFFER, Emilio: Código Procesal Penal. Anotado y concordado, $2^{\mathrm{a}}$ Edición, Editorial Jurídica de Chile, Santiago, 2001.

* ROJAS V., Sonia y ROJAS A., Luis: "Los Acuerdos Reparatorios en el Nuevo Proceso Penal", en La Victima y el Testigo en la Reforma Procesal Penal, Ministerio Público, División de Atención a las Víctimas y Testigos, Editorial Fallos del Mes, Santiago, 2003.

* ROXIN, Claus: Derecho penal parte general, Tomo I, La estructura de la teoría del delito, $2^{\mathrm{a}}$ edición, Editorial Civitas, Madrid, 1997.

* SILVA Sánchez, Jesús-María: La expansión del Derecho penal. Aspectos de la Política Criminal en las sociedades postindustriales, Editorial Civitas, Madrid, 2001.

* TAvolari O., Raúl: "Excepciones al Principio de Legalidad y Salidas Alternativas en el Nuevo Código Procesal Penal”, en Materiales de estudio para estudiantes. Universidad de Chile, 2000.

* ZÁrATE Campos, M.: "Los Acuerdos Reparatorios: Algunos comentarios a partir de las nociones de reparación y negociación”, Tesis presentada en el Diplomado sobre Reforma Procesal Penal: Aspectos dogmáticos, legales y de litigación en juicio oral, Universidad Católica del Norte, sede Coquimbo, Septiembre de 2001. www.acceso.uct.cl/congreso/docs/mzarate.doc 